\title{
Stress Corrosion Cracking Behavior of TP95S tube Steel in an Acidic Gas Field Environment
}

\author{
Yong $\mathrm{Li}^{1}$, Zhiyong $\mathrm{Liu}^{1,{ }^{*}}$, Le Ke ${ }^{1}$, Luyao Huang ${ }^{1}$, Cuiwei Du ${ }^{1}$, Xiaogang $\mathrm{Li}^{1}$ \\ ${ }^{1}$ Corrosion and Protection Center, Key Laboratory for Corrosion and Protection (MOE), University of \\ Science and Technology Beijing, Beijing 100083, China \\ *E-mail: liuzhiyong7804@126.com
}

doi: $10.20964 / 2016.06 .46$

Received: 9 September 2015 / Accepted: 30 March 2016 / Published: 4 May 2016

\begin{abstract}
Stress corrosion cracking (SCC) of TP95S tube steel was investigated through electrochemical measurement and electrochemical hydrogen charging, as well as immersion corrosion and slow strain rate tensile tests. The SCC mechanism of TP95S steel in the acidic gas field solution is mixed controlled by anodic dissolution (AD) and hydrogen embrittlement (HE). The SCC susceptibility of TP95S is lower at $100{ }^{\circ} \mathrm{C}$ than that at $60{ }^{\circ} \mathrm{C}$ because of abated HE. When the tensile stress reaches more than $70 \%$ of the yield strength of TP95S tube steel, TP95S exhibits SCC. Thus, stress applied to TP95S tube steel in service should be lower than $70 \%$ and $50 \%$ of the yield strength at $100{ }^{\circ} \mathrm{C}$ and 60 ${ }^{\circ} \mathrm{C}$, respectively. Furthermore, tensile stress decreases the service life of TP95S tube steel in the acidic gas field.
\end{abstract}

Keywords: TP95S tube steel; acidic gas field; stress corrosion cracking

\section{$\underline{\text { FULL TEXT }}$}

(C) 2016 The Authors. Published by ESG (www.electrochemsci.org). This article is an open access article distributed under the terms and conditions of the Creative Commons Attribution license (http://creativecommons.org/licenses/by/4.0/). 